\title{
Management of the Ageing Macula
}

\author{
E. L. CHUANG \\ Miami, Florida
}

\begin{abstract}
Summary
Age-related Macular Degeneration (AMD) is responsible for the majority of registered blindness in the elderly. Laser photocoagulation can be offered as a treatment of proven value to only a proportion of patients with neovascular AMD. Clinically, our expectations must be tempered by the high incidence of recurrent subretinal vessels, the anatomic limitations of treatable lesions and the large number of ageing eyes for which there is no place for laser. In addition to improvements in education, referral habits and the application of laser therapy which may have an impact upon visual loss due to AMD, there are promising directions to be explored in alternative modes of treatment and prevention.
\end{abstract}

It is well recognised that the leading cause of blindness in the elderly is AMD. ${ }^{1,2}$ This and alternative designations such as senile macular degeneration (SMD) are used by many authors to refer to all forms of macular ageing, whereas only those changes associated with loss of function are included under the designation AMD by others. The former definition is used here for drusen, retinal pigment epithelial detachment, geographic atrophy and subretinal (choroidal) neovascularisation, manifestations of ageing which do not occur sequentially but rather exist in an interrelated manner.

Only a small proportion of patients with age-related changes suffer significant visual loss. ${ }^{2}$ Though it is one of the least common manifestations of the ageing macula, subretinal neovascularisation (SRNV) or disciform degeneration is responsible for the vast majority of these blind eyes. ${ }^{3}$

A significant proportion of these eyes pass through a stage in which laser therapy can improve the visual prognosis. This review will concentrate upon neovascular complications of AMD, outlining the relevant studies of laser treatment, completed and in progress, and also cover limitations and failures of therapy. Those manifestations of macular ageing for which no treatment is currently appropriate will also be considered. Finally, mention will be made of less conventional therapeutic approaches under study and on the ultimate management, that is, possible prevention.

\section{State of The Art-Laser Treatment}

It is appropriate to begin discussion of laser treatment by reviewing briefly the effects of photocoagulation in the target and neighbouring tissues. ${ }^{4}$ These are based upon the conversion of light energy to heat, the effects of which are determined by irradiance, absorption and tissue pathlength. Factors such as power, duration and spot size comprise irradiance, while heat absorption depends upon the wavelength employed relative to pigments present in the tissues and is affected by heat conduction as well as by light absorption and scatter due to the lens. In the target tissues, the main heat-absorbing substances are melanin, xanthophyll and haemoglobin, each 
of which has a characteristic location (pathlength) and relative absorption of different wavelengths. The clinically available lasers include Argon Blue-green and Green only, Krypton Red and Yellow, and most recently, the tuneable Dye Laser with which a wavelength may be chosen to best suit the individual setting. 5

Melanin has a broad spectrum of absorption, such that its relative concentration in the retinal pigment epithelium (RPE) and choroid is the primary determinant of energy absorption. Spread of heat to neovascular complexes adjacent to the RPE and originating from the choroid is the principal means by which closure of SRNV occurs. Melanin concentration varies considerably with race and age: as the concentration of melanin decreases with age, higher power levels are needed in order to create the desired photocoagulative effects. Melanin absorbs longer wavelengths less than shorter ones. Therefore with Red, more energy penetrates the RPE to reach the choroid, a partial explanation for the deeper burns characteristic of Krypton Red versus Argon Blue-Green.

Haemoglobin absorbs Blue, Green and Yellow well, but longer wavelengths poorly. Therefore, retinal vascular and secondary inner retinal damage can be minimised by the use of Red, as has been demonstrated histologically. ${ }^{6}$ Furthermore, if there is a thin layer of blood associated with a neovascular membrane, relatively better penetration is afforded by Red wavelengths, delivering more energy to the deeper target tissues.

Xanthophyll absorbs Blue most, Green minimally and Yellow or Red least. Like melanin, its concentration is partially determined by race. Furthermore, as melanin concentration decreases with age, the use of increasing power levels in order to create an adequate burn potentially leads to more significant absorption by xanthophyll. The presence of xanthophyll in the central macula, primarily in the outer plexiform layer means that damage to the neurosensory retina can be minimised in this location by the use of longer wavelengths. With ageing, the lens contains increasing amounts of xanthophyll, leading to greater absorption and scatter of short wave- lengths which must also be taken into account in considering the effects of laser.

\section{Present Clinical Management of AMD}

Photocoagulation is the only effective modality presently available for the treatment of any of the sight-threatening complications of AMD, and is correctly applied only to neovascular lesions. Our currently accepted approach is based upon the results of three recent randomised clinical trials which have shown significantly improved outcome with Argon Blue-Green laser treatment for extrafoveal membranes in elderly populations. ${ }^{7-9}$ These studies varied in specific criteria used for patient selection, treatment or follow-up, but many features were common to all three. Eligible membranes causing symptoms were treated with heavy and confluent burns extending beyond the angiographic limits of the lesion. Visual results were better in eyes treated compared to those observed in all three studies. In the Macular Photocoagulation Study (MPS), visual loss of six or more lines of acuity was present in 60 per cent of untreated eyes $v s 25$ per cent of treated eyes 18 months after treatment. ${ }^{7}$ Stable or improved vision was twice as likely in treated eyes at six months. Similarly, in the British and French studies, all analyses favoured treatment over observation. ${ }^{8,9}$

Unfortunately, obtaining and maintaining the benefits of treatment goes far beyond the technical application of laser. Persistent or recurrent SRNV following laser is an all too frequent event. All three randomised studies as well as other retrospective analyses which have included Krypton Red-treated eyes have identified open vessels in close to 60 per cent of eyes after intended obliterative photocoagulation. ${ }^{10-13}$ The vast majority of these arise from the site of the original neovascularisation and its treatment, with only 8 per cent of 'recurrent' membranes in treated MPS eyes located independently from treatment scars. Virtually all the recurrences arise from the foveal treatment edge, underlining the well-recognised tendency of neovascular membranes to grow toward the foveola and perhaps modified laser absorption in this location as well as reluctance to apply BlueGreen laser close to xanthophyll pigment. 
The majority appear relatively early: with almost five year follow-up in the MPS, over 70 per cent of recorded recurrences were identified within the first year. ${ }^{10}$ It is of significance that analysis to date has not identified specific features other than distance from the foveal avascular zone, which might be useful predictors of eyes at higher risk for recurrence in Argon treated eyes. The long-term visual outcome is worsened because of the high number of recurrences, but still remains better than no treatment at all since laser can be reapplied in eyes with recurrent SRNV which continue to meet treatment criteria. ${ }^{14}$

The nature of recurrences reflects not only features of the biologic nature of SRNV but also less than optimal aspects of our presently accepted treatment approach. If we can better understand and manage this common sequel to laser treatment in neovascular AMD, the visual prognosis in macular ageing will undoubtedly improve. Though the use of Argon Blue-Green is the only modality presently supported by results of randomised studies, there is ample theoretical and mounting clinical experience to indicate that other wavelengths may be more suitable in many circumstances..$^{415-17}$. The choice of wavelength should be directed by the principles outlined above applied to variations in membrane location, background fundus pigmentation, the amount of xanthophyll pigment, or the presence of subretinal fluid, blood or reactive pigment. For example, in instances in which there is little melanin present in either the RPE or choroid, Argon Green with higher absorption by haemoglobin and melanin may be a more appropriate choice. The use of Red, Green, or Yellow may allow both treatment of membranes closer to fixation and more adequate obliteration on the foveal side of the lesion. Prospective trials of Krypton Red and Argon Green for SRNV less than 200 microns from, but not beneath the foveola are well underway in the United Kingdom and in the United States of America in hopes of answering this question.

Beyond more effective treatment of primary or recurrent SRNV, steps other than laser can be taken to improve visual outcome when disciform degeneration occurs. The timing of evaluation is critical since it is recog- nised that the biologic behaviour of NVMs includes an initial period of greatest activity and growth. ${ }^{18}$ Experience has identified an interval of weeks from the onset of symptoms beyond which laser therapy results in a poorer visual outcome. ${ }^{19}$ After treatment, patients should be clearly and repeatedly informed of the means and need to monitor central vision and of the importance of seeking immediate attention should symptoms arise. They and referring eye care specialists must also have ready access to appropriate evaluation. These measures should enhance our ability to approach the highest possible success rate afforded by photocoagulation.

In the best of circumstances, there will always be individuals in whom the location of an active NVM will begin or become subfoveal, so that there can be no hope for normal central vision. In such instances, laser may still improve final visual function. It has been proposed that the size of the ultimate scotoma can be limited by photocoagulation of subfoveal SRNV. ${ }^{20}$ Patients learn to use neighbouring photoreceptors after loss of the fovea.$^{21}$ Also, there is evidence that patients with smaller scotomas have better functional vision, at least for some tasks. ${ }^{22}$ This controversial technique would necessarily include intentional destruction of surrounding functioning retina to obliterate effectively choroidal neovascularisation. A randomised trial is being organised as an extension of the MPS to assess the value of subfoveal treatment, but such therapy is not recommended at present.

\section{Manifestations of AMD not Appropriate for Photocoagulation}

Three other manifestations of ageing of the macula are presently unsuitable for treatment. SRNV may be strongly suspected, but not defineable angiographically, producing poorly circumscribed yet progressive hyperfluorescence. Such an appearance may accompany a distinct membrane as a flat rim of hyperfluorescence which only in retrospect has gradually and quietly enlarged. A recent study suggests that eyes with such 'occult' membranes maintain better vision under observation than with photocoagulation. ${ }^{23} \mathrm{On}$ the one hand, their often benign behaviour is quite compatible with prolonged good acuity, 
while on the other, there is significant risk of incomplete treatment with a high probability of accelerated activity.

Retinal pigment epithelial detachments (RPED) as a manifestation of AMD are considered exudative by some authors, implying the presence of SRNV. On the contrary, RPEDs are not necessarily associated with new vessels. ${ }^{24-27}$. They may remain stable with quite good vision or even resolve spontaneously. SRNV becomes apparent in approximately one-third of what begin as serous RPEDs, more commonly in those which tend to be central, large, associated with serous retinal detachment, and angiographically late filling and irregularly fluorescent ${ }^{26,27}$ Even so, retinal function may be relatively good over vascularised RPEDs since the anatomic arrangement of vascular supply (choroid-derived new vessels), RPE and photoreceptors may be preserved. The visual prognosis for RPEDs is therefore certainly not uniformly poor. In a prospective, randomised trial, visual outcome was statistically worsened by laser treatment of RPED. ${ }^{28}$ In some instances, neovascular vessels previously contained beneath the RPE may have been stimulated and allowed to penetrate into the subretinal space. In others, photocoagulation induced tears of the RPE. Since it can initiate or accelerate deterioration in a condition with a variable prognosis, laser is not recommended to all RPEDs. Whether a subset of these lesions may fare better with photocoagulation remains to be determined, although such a group was not identified in the previous study. ${ }^{28}$

Well-circumscribed atrophy of the outer retina may appear as a late manifestation of AMD. ${ }^{29,30}$ This has been referred to as geographic or areolar atrophy. Though histologic evidence of choroidal neovascularisation often coexists with atrophic changes, ${ }^{31}$ it is uncommon clinically to find concurrent or subsequent disciform degeneration in eyes with geographic atrophy. ${ }^{29}$ Long after either active SRNV or after a tear of the RPE, an appearance may evolve which clinically simulates primary atrophy. Laser photocoagulation is not appropriate for any of these atrophic forms of AMD.

\section{Second Eyes and Drusen Alone}

The next concern of both the patient and the ophthalmologist is the other eye. For individuals with disciform degeneration in one eye, the risk of developing SRNV in the second eye lies in the range of $12-15$ per cent per year..$^{32,33}$ Relatively greater risk may exist for eyes with many, large or highly confluent drusen.

What about individuals with drusen alone in each eye? There are no prophylactic measures by which the risk of neovascular complications can be reduced nor are there means of preventing the mild loss of vision which may accompany drusen itself. The epidemiologic evidence implies that of the vast numbers of elderly individuals manifesting these age-related changes in Bruch's membrane, only a small number are destined to develop SRNV. The actual risk is difficult to determine but cumulatively is probably in the neighbourhood of 12 per cent over five years. ${ }^{34}$ Characteristics which may indicate a higher risk for the development of SRNV include a family history of disciform degeneration and the presence of significant confluence of drusen or focal hyperpigmentation. ${ }^{29.34}$

As more effective methods of treatment are developed, it becomes increasingly relevant to address the issue of how best to screen for treatable disciforms. Should all patients with drusen be appraised of the possibility of SRNV, the symptoms and what steps should be taken? Such a policy and the number of resultant examinations would have an enormous impact upon the eye-care services. In this regard, there is hope for the development of low cost methods of screening and further identification of predictors of eyes at highest risk.

\section{Low Vision Aids}

For those in whom no further therapy is possible, low vision clinics play an important role in assessing and utilising remaining visual function. The practical limit appears to be vision of finger counting at approximately one metre. This of course depends as much upon the adaptability, physical status and motivation of the patient as upon the macular lesion itself. Perhaps 70 per cent of those referred 
can be helped substantially by these techniques. ${ }^{35}$

\section{Other Approaches}

Several lines of research suggest alternative approaches which may be useful against SRNV beside obliterative laser treatment. Normal Bruch's membrane is an avascular structure, the barrier function of which breaks down with age. ${ }^{36}$ There is considerable evidence for the role of cellular mediators such as macrophages in the production of SRNV. ${ }^{37.38}$ Vasoactive factors operating between RPE and choroidal vessels have been postulated which may also be important in the genesis of choroidal neovascularisation. ${ }^{39}$ Agents such as corticosteroids or growth suppressants might be used to manipulate cellular components or the presumed angiogenic stimulus for SRNV. ${ }^{40}$ There may however be undesireable effects upon RPE, inflammatory and other cells which participate in repair and/or limit neovascular growth. ${ }^{41.42}$

A great deal has been learned from cell culture, especially of RPE cells, now an established research tool in vision research. Various factors have been identified by which intra and intercellular metabolic systems can be modified..$^{43,44}$ Injection of cultured RPE cells beneath the retina is under investigation ${ }^{45}$ and studies are in progress on the transplantation of retinal tissues. ${ }^{46}$ In the future, it may not be totally unrealistic to envision cell repopulation in some settings of AMD.

\section{Prevention?}

Thus far, available and promising therapeutic approaches have been discussed which can be applied to eyes after they have developed advanced ageing changes. Instead, can measures be taken which modify or even prevent the vision-threatening alterations which occur with ageing?

Studies of changes in the cellular microenvironment of the retina with age show that there is clearly a link between continuous photoreceptor outer segment turnover, disc phagocytosis, accumulation of lipofuscin, and changes in Bruch's membrane which lead to the clinical manifestations of AMD. As outlined by Feeney-Burns,${ }^{47}$ lipofuscin formation proceeds through a complex process which includes the action of light-induced, oxygenderived free radicals on polyunsaturated fatty acids, components of all cell membranes. Metabolic systems controlling or limiting lipid peroxidation can be modified by a number of natural antioxidants in the retina such as superoxide dismutase, ascorbate, melanin, taurine and vitamin E. ${ }^{47}$ Animal models have been established in order to manipulate dietary composition, vitamin supplementation or deletion, and light exposure in order to gain insight into pathogenesis as well as to identify points at which intervention may be attempted. ${ }^{48,49}$ It may someday be possible to benefit in man from the control of dietary lipids, ocular protection from potentially hazardous wavelengths or alteration of agerelated loss of melanin from the RPE. Whatever the results of such investigations, from what we know of the progressive nature and early onset of ageing changes, such measures would have to be initiated virtually in childhood in order to be useful.

In summary, we are faced with quite variable consequences of ageing in the macula, only one of which, subretinal neovascularisation can currently be approached with treatment of proven benefit. Even with laser treatment, a discouragingly small proportion of affected eyes can be successfully treated. However, advances in photocoagulation techniques and continuing research will hopefully improve prospects for the future management of the ageing macula.

The author is grateful to Professor A. C. Bird for review of the manuscript.

\section{References}

${ }^{1}$ Sorsby A: The incidence and causes of blindness in England and Wales 1948-1962. Reports on Public Health and Medical Subjects (No. 114). London. HMSO, 1966; 11-14.

${ }^{2}$ Leibowitz HM, Krueger DE, Maunder LR, et al: The Framingham Eye Study Monograph; an ophthalmological and epidemiological study of cataract, glaucoma, diabetic retinopathy, macular degeneration and visual acuity in a general population of 2631 adults, 1973-1975. Surv. Ophthalmol. 1980, 24 (Suppl): 428-71.

${ }^{3}$ Hyman LG: Senile macular degeneration: an epidemiologic case control study. Thesis, the Johns Hopkins University, Baltimore, 1981.

${ }^{4}$ Mainster MA: Wavelength selection in macular photocoagulation: tissue optics, thermal effects, 
and laser systems. Ophthalmology 1986, 93: 952-8.

${ }^{5}$ L'Esperance FA: Clinical applications of the organic dye laser. Ophthalmology 1985, 92: 1592-600.

${ }^{6}$ Marshall J, Bird AC: A comparative histopathological study of argon and krypton laser irradiations of the human retina. Br. J. Ophthalmol. 1979, 63: 657-68.

${ }^{7}$ Macular Photocoagulation Study Group: Argon laser photocoagulation for senile macular degeneration: results of a randomized clinical trial. Arch. Ophthalmol. 1982, 100: 912-8.

${ }^{8}$ Moorfields Macular Study Group: Treatment of senile disciform macular degeneration: a singleblind randomized trial by argon laser photocoagulation. Br. J. Ophthalmol. 1982, 66: 74553.

${ }^{9}$ Coscas G, Soubrane G: Photocoagulation des néovaisseaux sous-rétiniens dans la dégénérescence maculaire sénile par laser à argon: Résultats de l'étude randomisée de 60 cas. Bull. et Mém. Soc. Fr. Ophthalmol. 1983, 94: 149-54.

${ }^{10}$ Macular Photocoagulation Study Group: Recurrent choroidal neovascularization after argon laser photocoagulation for neovascular maculopathy. Arch. Ophthalmol. 1986, 104: 503-12.

${ }^{11}$ Chisholm IH: The recurrence of neovascularisation and late visual failure in senile disciform lesions Trans. Ophthalmol. Soc. UK 1983, 103: 354-9.

12 Olk RJ, Burgess DB: Treatment of recurrent juxtafoveal subretinal neovascular membranes with krypton red laser photocoagulation. Ophthalmology 1985, 92: 1035-46.

${ }^{13}$ Sorenson JA, Yannuzzi LA, Shakin JL: Recurrent subretinal neovascularization. Ophthalmology 1985, 92: 1059-74.

${ }^{14}$ Macular Photocoagulation Study Group: Argon Laser photocoagulation for neovascular maculopathy: three-year results from randomized clinical trials. Arch Ophthalmol 1986, 104: 694701.

${ }^{15}$ Bird AC, Grey RHB: Photocoagulation of disciform macular lesions with krypton laser. $B r . J$. Ophthalmol. 1979, 63: 669-73.

16 Yannuzzi LA: Krypton red laser photocoagulation for subretinal neovascularization. Retina 1982, 2: 29-46.

${ }^{17}$ Smiddy WE, Fine SL, Green WR, Glaser BM: Clinicopathologic correlation of krypton red, argon blue-green and argon green laser photocoagulation in the human fundus. Retina 1984, 4: 15-21.

${ }^{18}$ Teeters VW, Bird AC: The development of neovascularization of senile disciform macular degeneration. Am. J. Ophthalmol. 1973, 76: $1-18$.

${ }^{19}$ Grey RHB, Bird AC, Chisholm IH: Senile disciform macular degeneration: features indicating suitability for photocoagulation. Br. J. Ophthalmol. 1979, 63: 85-9.

${ }^{20}$ Guyer DR, Fine SL, Maguire MG, Hawkins BS, Owens SL, Murphy RP: Subfoveal choroidal neovascular membranes in age-related macular degeneration: visual prognosis in eyes with relatively good initial visual acuity. Arch. Ophthalmol. 1986, 104: 702-5.

${ }^{21}$ Timberlake GT, Mainster MA, Peli E, Augliere RA, Essock EA, Arend LE: Reading with a macular scotoma. Invest. Ophthalmol. Vis. Sci. 1986, 27: 1137-47.

${ }^{22}$ Bressler SB, Bressler NM, Fine SL, McCormick P, Auer C: Subfoveal neovascular membranes in senile macular degeneration: relationship between membrane size and visual prognosis. Retina 1983, 3: 7-11.

${ }^{23}$ Soubrane G, Coscas G, Francais C: Laser treatment of subretinal new vessels in age-related macular degeneration. Am. J. Ophthalmol. (in press).

${ }^{24}$ Braunstein RA, Gass JDM: Serous detachments of the retinal pigment epithelium in patients with senile macular disease. Am. J. Ophthalmol. 1979, 88: 652-60.

${ }^{25}$ Meredith TA, Braley RE, Aaberg TA: Natural history of serous detachments of the retinal pigment epithelium. Am. J. Ophthalmol. 1979, 88: 643-51.

${ }^{26}$ Casswell AG, Kohen D, Bird AC: Retinal pigment epithelial detachments in the elderly: classification and outcome. Br. J. Ophthalmol. 1985, 69: 397-403.

${ }^{27}$ Elman MJ, Fine SL, Murphy RP, Patz A, Auer C: The natural history of serous retinal pigment epithelium detachment in patients with age-related macular degeneration. Ophthalmology 1986, 93: 224-30.

${ }^{28}$ Moorfields Macular Study Group: Retinal pigment epithelial detachments in the elderly: a controlled trial of argon laser photocoagulation. Br. J. Ophthalmol. 1982, 66: 1-16.

${ }^{29}$ Gass JDM: Drusen and disciform macular detachment and degeneration. Arch. Ophthalmol. 1973, 90: 206-17.

${ }^{30}$ Sarks SH: Ageing and degeneration in the macular region: a clinico-pathological study. $\mathrm{Br} . \mathrm{J}$. Ophthalmol. 1976, 60: 324-41.

${ }^{31}$ Green WR, Key SN: Senile macular degeneration: a histopathologic study. Trans. Am. Ophthalmol. Soc. 1977, 75: 180-254.

${ }^{32}$ Gregor Z, Bird AC, Chisholm IH: Senile disciform macular degeneration in the second eye. Br. J. Ophthalmol. 1977, 61: 141-7.

${ }^{33}$ Strahlman ER, Fine SL, Hillis A: The second eye of patients with senile macular degeneration. Arch. Ophthalmol. 1983, 101: 1191-3.

${ }^{34}$ Smiddy WE, Fine SL: Prognosis of patients with bilateral macular drusen. Ophthalmology 1984, 91: 271-7.

${ }^{35}$ Silver J: Optical aids in low vision. In Cullinan T. Visual disability in the elderly. London: Croom Helm 1986: 80-84.

${ }^{36}$ Sarks SH: New vessel formation beneath the retinal pigment epithelium in senile eyes. Br. $J$. Ophthalmol. 1973, 57: 951-65.

${ }^{37}$ Grindle CFJ, Marshall J: Ageing changes in Bruch's membrane and their functional implications. Trans. Ophthalmol. Soc. UK 1978, 98: 172-5. 
${ }^{38}$ Pollack A, Korte GE, Heriot WJ, Henkind P. Ultrastructure of Bruch's membrane after krypton laser photocoagulation. II. Repair of Bruch's membrane and the role of macrophages. Arch. Ophthalmol. 1986, 104: 1377-82.

${ }^{39}$ Korte GE, Reppucci V, Henkind P: RPE destruction causes choriocapillaris atrophy. Invest. Ophthalmol. Vis. Sci. 1984, 25: 1135-45.

${ }^{40}$ Ishibashi T, Miki K, Sorgente N, Patterson R, Ryan SJ: Effects of intravitreal administration of steroids on experimental subretinal neovascularisation in the subhuman primate. Arch. Ophthalmol. 1985, 103: 708-11.

${ }^{41}$ Smiddy WE, Fine SL, Quigley HA, Dunkelberger G, Hohman RM, Addicks EM: Cell proliferation after laser photocoagulation in primate retina: an autoradiographic study. Arch. Ophthalmol. 1986, 104: 1065-9.

${ }^{42}$ Miller H, Miller B, Ryan SJ: Laser-induced subretinal neovascularization: development and involution. (In press.)

${ }^{43}$ Bryan JA, Campochiaro PA: A retinal pigment epithelial cell-derived growth factor(s). Arch. Ophthalmol. 1986, 104: 422-5.
${ }^{44}$ Flood MT, Bridges CDB, Alvarez RA, Blaner WS, Gouras P: Vitamin A utilization in human retinal pigment epithelial cells in vitro. Invest. Ophthalmol. Vis. Sci. 1983, 24: 1227-35.

${ }^{45}$ Gouras P, Flood MT, Kjeldbye H, Bilek MK, Eggers $\mathrm{H}$ : Transplantation of cultured human retinal pigment epithelium to Bruch's membrane of the owl monkey's eye. Curr. Eye Res. 1985, 4: 25365.

${ }^{46}$ Turner JE, Blair JR: Neonatal rat retinal grafts integrate into the lesion site of adult host retina. ARVO Abstracts. Invest. Ophthalmol. Vis. Sci. 1986, 26 (Suppl): 336.

${ }^{47}$ Feeney-Burns L, Berman ER, Rothman $\mathrm{H}$ : Lipofuscin of human retinal pigment epithelium. Am. J. Ophthalmol. 1980, 90: 783-91.

${ }^{48}$ Robison WG, Kuwabara T, Bieri JG: Vitamin E deficiency and the retina: photoreceptor and pigment epithelial changes. Invest. Ophthalmol. Vis. Sci. 1979, 18: 683-90.

${ }^{49}$ Woodford BJ, Tso MOM and Lam K-W: Reduced and oxidized ascorbates in guinea pig retina under normal and light-exposed conditions. Invest. Ophthalmol. Vis. Sci. 1983, 24: 862-7. 